\title{
Progresso temporal do chumbinho em diferentes genótipos de pessegueiro
}

\author{
Leandro Luiz Marcuzzo ${ }^{1}$, Juliano Evandro dos Santos ${ }^{1}$
}

${ }^{1}$ Instituto Federal Catarinense - IFC/Campus Rio do Sul, CP 441, CEP 89.163-356, Rio do Sul, SC, juliano.tomate@yahoo.com.br Autor para correspondência: Leandro Luiz Marcuzzo (marcuzzo@ifc-riodosul.edu.br)

Data de chegada: 23/08/2016. Aceito para publicação em: 25/04/2017.

$10.1590 / 0100-5405 / 168152$

\section{RESUMO}

Marcuzzo, L.L.; Santos, J.E. Progresso temporal do chumbinho em diferentes genótipos de pessegueiro. Summa Phytopathologica, v.43, n.3, p.239-242, 2017.

O chumbinho do pessegueiro causado por Wilsonomyces carpophilus é uma das doenças comumente encontrada na cultura, comprometendo a área foliar e consequentemente reduzindo a produção e a qualidade dos frutos. Considerando que o comportamento desta doença é pouco conhecido, esse trabalho teve como objetivo avaliar o progresso temporal ao longo do ciclo produtivo em diferentes genótipos de pessegueiro. $\mathrm{O}$ experimento foi realizado no pomar de pessegueiro do Instituto Federal Catarinense -IFC/Campus Rio do Sul. Foram avaliados os genótipos Granada, Dourado 1, Dourado 2, Douradão, Ouro, Chimarrita, Flordaprince, Premier, Aurora e Della Nona. Selecionaram-se quatro plantas de cada genótipo e avaliou-se a severidade estimada da doença semanalmente, após o inicio da brotação, em 16 folhas de cada planta com auxilio de uma escala diagramática. A curva de progresso da doença para cada um dos genótipos foi ajustada ao modelo logístico, já que a severidade observada correspondeu ao modelo e foi confirmada pela coerência entre os pontos estimados e pelo resíduo. Foi verificado que os genótipos FlordaPrince e Premier apresentaram as maiores taxas $(0,329)$ de progresso, enquanto que Douradão a menor $(0,223)$. Verificou-se que o genótipo Dourado 1 apresentou o pico máximo da severidade com $10,5 \%$ e que Granada teve o menor acúmulo da doença com 4,5\%. Os genótipos de pessegueiro apresentaram diferentes comportamentos do progresso temporal ao chumbinho do pessegueiro.

Palavras-chave: Prunus persica, epidemiologia, Wilsonomyces carpophilus.

\section{ABSTRACT}

Marcuzzo, L.L.; Santos, J.E. Marcuzzo, L.L.; Santos, J. E. Temporal progress of shot hole in different peach genotypes. Summa Phytopathologica, v.43, n.3, p.239-242, 2017.

Shot hole caused by Wilsonomyces carpophilus is a disease commonly found in peach orchards, affecting the leaf area and consequently reducing fruit production and quality. Considering that the behavior of this disease is scarcely known, this study aimed to evaluate the temporal progress throughout the production cycle in different peach genotypes. The experiment was carried out in a peach orchard at "Instituto Federal Catarinense"-IFC / Rio do Sul Campus. Evaluated genotypes were: Granada, Dourado 1, Dourado 2, Douradão, Ouro, Chimarrita, Flordaprince, Premier, Aurora and Della Nona. Four plants from each genotype were selected and estimated disease severity was weekly evaluated after the beginning of sprouting, on 16 leaves from each plant, using a diagrammatic scale. The disease progress curve for each genotype was adjusted to a logistic model, since the observed severity corresponded to the model and was confirmed by the consistency between the estimated points and the residue. Genotypes Flordaprince and Premier showed the highest disease rates (0.329), while Douradão (0.223) had the lowest rate. Genotype Dourado 1 showed the highest severity peak, $10.5 \%$, and Granada had the lowest disease accumulation, $4.5 \%$. Peach genotypes had different temporal progress behaviors to shot hole.

Keywords: Prunus persica, epidemiology, Wilsonomyces carpophilus.

A área e o consumo de pêssego [Prunus persica (L.) Batsch] aumentou nos últimos anos, mas mesmo assim a produção é insuficiente para atender a demanda interna (10).

$\mathrm{Na}$ cultura são diversos os fatores que contribuem para a sua baixa produtividade e entre esses, estão às doenças de diversas etiologias, as quais causam prejuízos significativos à cultura. Entre as doenças fúngicas foliares esta o chumbinho ou furo de bala, causado por Wilsonomyces carpophilus (Lév) Adaskaveg, Ogawa \& Butler (sin. Stigmina carpophila, Coryneum beyerinckii, Clasterosporium carpophilum), que pode comprometer a produtividade do pessegueiro (6).

O fungo sobrevive em gema e ramos doente sendo disseminado pela água da chuva. Os conídios podem permanecer viáveis por meses nos ramos, infectando gemas e posteriormente as folhas. Necessita de um período de 24 horas de ocorrência de molhamento foliar para haver infecção e temperatura em torno de $20^{\circ} \mathrm{C}(6)$. Nas primaveras quentes e úmidas é comum encontrar manchas entre cinco e sete dias, após o inicio de um período chuvoso (1).

O uso de genótipos resistentes é uma das formas de manejo dessas doenças, porém é necessária a avaliação do comportamento temporal da doença entre genótipos (2). Entre as formas de caracterizar o desenvolvimento de fitopatógenos, a curva de progresso temporal é a melhor representação de uma epidemia. A interpretação do formato dessas curvas e seus componentes, como a taxa e a severidade final podem ser usadas para determinar a o progresso da doença de genótipos $(3,4)$. 
Como não se dispõe de informação sobre o assunto, o objetivo deste trabalho foi avaliar o comportamento quanto ao progresso temporal do chumbinho em diferentes genótipos de pessegueiro.

O trabalho foi realizado em pomar de coleção de genótipos de pessegueiro localizado no Instituto Federal Catarinense, IFC, Campus de Rio do Sul, no município de Rio do Sul, SC, com latitude, $27^{\circ} 11^{\text {' }}$ 22 " S, longitude, 49 39' 48" W e altitude de 655 metros acima do nível do mar.

O período de avaliação foi entre 01/09/2010 a 24/03/2011, durante 30 semanas. Os genótipos avaliados foram Aurora, Chimarrita, Della Nona, Douradão, Dourado 1, Dourado 2, Flordaprince, Granada, Ouro e Premier. Todos os genótipos estavam com 12 anos de idade sobre o porta-enxerto Capdeboscq conduzidos em forma de taça. $\mathrm{O}$ espaçamento no pomar era de 6,5 metros entre linhas e 5 metros entre plantas. O delineamento experimental foi de blocos casualizados constituídos por uma planta por repetição e quatro repetições de cada genótipo.

O solo no local do experimento era do tipo cambissolo distrófico, relevo suavemente ondulado, $\mathrm{com} \mathrm{pH}$ em água $=6,1$, Fósforo $=3,0$ $\mathrm{mg} / \mathrm{dm}^{3}$, Potássio $=72,0 \mathrm{mg} / \mathrm{dm}^{3}$, Matéria orgânica $=3,4 \%$ e Argila $=21 \%$. Os tratos culturais foram realizados conforme o sistema de produção da cultura (7).

O momento da aplicação de inseticidas foi indicado pelo monitoramento da presença da praga com armadilha contendo suco de uva. A temperatura média durante a condução do experimento foi de $18^{\circ} \mathrm{C}$ com acumulado de $768 \mathrm{~mm}$ de precipitação.

A avaliação da severidade do chumbinho foi realizada semanalmente após o início da brotação em 16 folhas previamente marcadas por planta, totalizando 64 folhas avaliadas por genótipo. A severidade estimada do chumbinho foi baseada em uma escala diagramática proposta por Challiol et al. (5) que apresenta severidade foliar de 0,$25 ; 0,66 ; 1,71$; 4,$39 ; 10,80$ e $24,23 \%$.

Modelos não lineares, comumente usados para representar crescimento de epidemias como o Logístico e o de Gompertz foram usados para ajuste com os dados observados utilizando o software $\mathrm{R}$ versão 2.15.1(8). Os critérios estabelecidos para comparação dos modelos, em função da qualidade do ajustamento dos dados foram: a) erro padrão da estimativa; b) estabilidade dos parâmetros; c) erro padrão dos resíduos; d) visualização da distribuição dos resíduos ao longo do tempo e e) pseudo $\mathrm{R}^{2}$.

O modelo logístico descrito por: $\mathrm{y}=\mathrm{ymax} /(1+\exp (-\ln (\mathrm{yo} /(\mathrm{ymax}-$ yo)-r*x)), em que y é a intensidade final de doença; ymax, intensidade máxima da doença; $\ln ($ yo/(ymax-yo) refere-se a função de proporção da doença na primeira observação; $r$ corresponde à taxa; e x, ao tempo em semanas, foi escolhido para representar o progresso do chumbinho do pessegueiro. Esse modelo foi o que apresentou o melhor ajuste quanto à curva de progresso da doença (Figura 1), devido o chumbinho ser uma doença que evolui gradativamente a medida que inicia os primeiros sintomas.

A análise dos dados e as equações originadas pelo modelo logístico (Tabela 1) resultaram em um coeficiente de determinação significativo, e a severidade observada correspondeu ao modelo, confirmada pela coerência entre os pontos estimados e do resíduo (erro) nas 30 semanas de avaliação (Figura 1).

No presente trabalho, a detecção do chumbinho foi registrada na segunda semana em todos os cultivares e seguiu de forma gradativa até a vigésima primeira (Figura 1). Após esse período houve pouca alteração na intensidade da doença nas folhas, fato que provavelmente pose ser atribuído a efeitos do ambiente. O genótipo Douradão se diferenciou dos demais, pois a partir da quinta semana houve incremento da severidade, o qual foi crescente até o fim da avaliação em decorrência do inóculo que era produzido no pomar (Figura 1).

A taxa de progresso da doença foi diferente entre os genótipos (Tabela 1). No genótipo FlordaPrince houve a maior taxa $(\mathrm{r}=0,329)$ devido à maior severidade $(6,3 \%)$ da doença durante o período avaliado, mas com taxa similar ao Premier que teve severidade de $5,8 \%$. Barbosa et al. (2) também constatou severidade superior em FlordaPrince quando avaliou sua reação. O genótipo Granada foi o que teve menor acúmulo da doença com $4,5 \%$ e o oposto ocorreu com o Dourado 1, que decorrente da alta severidade da doença $(10,5 \%)$, resultou em taxa de 0,249 . O Douradão teve a menor taxa $(0,223)$, mas apresentou uma severidade final de $6,1 \%$ (Tabela 1$)$.

No entanto, o desenvolvimento da doença é dependente da presença do patógeno no ciclo anterior devido a presença de algumas folhas na planta e o início da infecção é relacionado à quantidade de inóculo disponível na área e duração do molhamento contínuo das folhas e temperatura favorável nesse período (3). Para o chumbinho há poucas informações na literatura sobre o assunto, e quando Challiol et al. (5) utilizaram a severidade para avaliar no genótipo Chimarrita em sistemas de produção convencional e integrado não descrevendo o progresso da doença. Tutida et al. (9) avaliaram o chumbinho em ameixeira sob diferentes doses de nitrogênio e potássio quantificando o comportamento da incidência ao longo do tempo, mas sem ajustar o progresso da doença a um modelo temporal.

Conclui-se que os genótipos avaliados apresentaram diferentes

Tabela 1. Coeficiente de determinação $\left(\mathrm{R}^{2}\right)$ e os parâmetros estimados pelo modelo logístico ajustado aos dados de progresso do chumbinho do pessegueiro em diferentes genótipos

\begin{tabular}{|c|c|c|c|c|}
\hline Genótipo & ymax & yo & $\mathbf{r}$ & $\mathbf{R}^{2}$ \\
\hline Granada & 0,045 & 3,117 & 0,246 & 0,989 \\
\hline Douradão & 0,061 & 3,275 & 0,223 & 0,991 \\
\hline Ouro & 0,050 & 4,224 & 0,287 & 0,997 \\
\hline Flordaprince & 0,063 & 4,175 & 0,329 & 0,995 \\
\hline Premier & 0,058 & 3,799 & 0,329 & 0,991 \\
\hline Dourado 1 & 0,105 & 2,689 & 0,249 & 0,969 \\
\hline Dourado 2 & 0,065 & 3,127 & 0,248 & 0,992 \\
\hline
\end{tabular}

y=ymax/(1+exp(-ln(yo/(ymax-yo)-r*x)), em que y é a intensidade final de doença; ymax, intensidade máxima da doença; ln(yo/(ymax-yo) refere-se a função de proporção da doença na primeira observação; $r$ corresponde à taxa; e $\mathrm{x}$, ao tempo em semanas. 

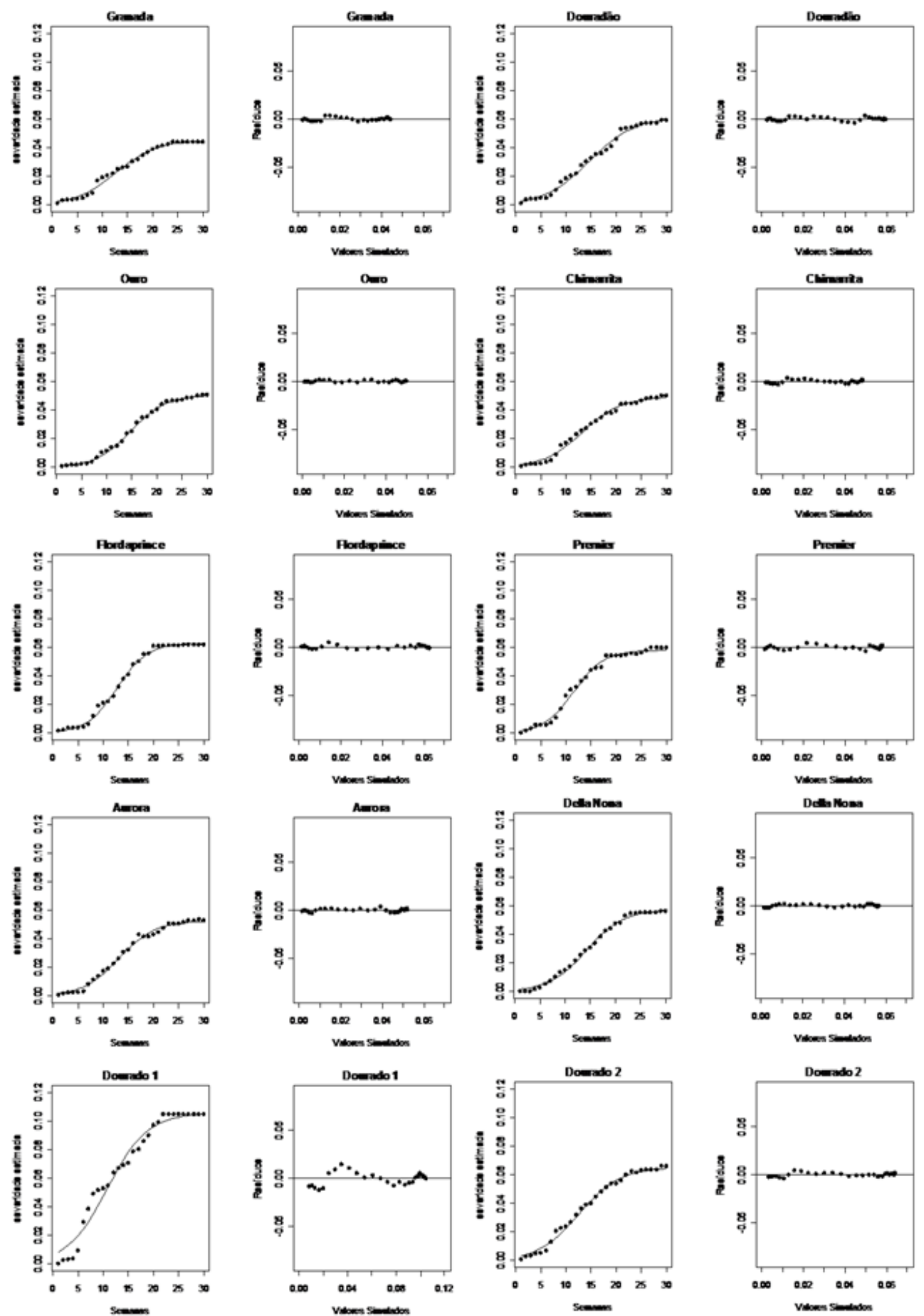

Figura 1. Curva da severidade estimada do progresso do chumbinho em diferentes genótipos de pessegueiro e seus respectivos resíduos ajustados pelo modelo logístico. 
comportamentos de progresso quanto ao chumbinho, no entanto, o genótipo Granada apresentou a menor intensidade da doença, enquanto que Dourado 1 a maior, apesar de que a menor taxa foi verificado no genótipo Douradão.

\section{REFERÊNCIAS}

1. Andrade, E. R. Doenças do pessegueiro e da ameixeira e seu controle no Estado de Santa Catarina. Florianópolis: EPAGRI, 1995. 52p. (EPAGRI. Boletim Técnico, 71).

2. Barbosa, W. Ojima, M.; Campo-Dall'orto, F.A.; Martins, F.P.; Castro, J.L.; Santos, R.R. Avaliação de pessegueiros e nectarineiras introduzidos no Brasil, procedentes da Flórida, EUA. Scientia agricola. Piracicaba, v.54, n.3, p.152-159, 1997.

3. Bergamim Filho, A.; Amorim, L. Doenças de plantas tropicais: epidemiologia e controle econômico. São Paulo: Ceres, 1996, 289p.

4. Campbell, C.L.; Madden, L.V. Introduction to plant disease epidemiology. New York : Wiley Interscience, 1990. 532p.

5. Challiol, M.A.; May-De-Mio, L.L.; Cuquel, F.L.; Monteiro, L.B.; Monte
Serrat, B.; Motta, A.C.V.; Ribeiro Júnior, P.J. Elaboração de escala diagramática para furo de bala e avaliação de doenças foliares em dois sistemas de produção de pessegueiro. Revista Brasileira de Fruticultura, Jaboticabal, v.28, n.3, p.391-396, 2006.

6. Martins, M.C.; Betti, J.A; Leite, R.M.V.B.C.; Leite, R.P.; Amorim, L. Doenças de rosáceas de caroço. In: Kimati, H.; Amorim, L.; Rezende, J.A.M.; Bergamim Filho, A.; Camargo, L.E.A. Manual de Fitopatologia: doenças de plantas cultivadas. São Paulo: Ceres, v.2,3 ed. Cap.62. p.545-557, 2005.

7. Medeiros, C.A.B.; Raseira, M.C.B. A cultura do pessegueiro. Brasília: EMBRAPA-SPI, 1998. 350p.

8. R Development Core Team (2012). R: A language and environment for statistical computing. R Foundation for Statistical Computing, Vienna, Austria. Disponível em: <http://www.R-project.org>. Acesso em: 15 fev. 2016.

9. Tutida, I.; May-De-Mio, L.L.; Motta, A.C.; Rosa, J.M.C. Incidência e severidade do "furo de bala" em folhas da ameixeira sob doses de nitrogênio e potássio. Ciência Rural, Santa Maria, v.37, n.5, p.1227-1234, 2007.

10. Zanette, F.; Biasi, L.A. Introdução à fruteiras de caroço. In: Monteiro, L.B.; May-De-Mio, L.L.; Serrat, B.M. (Ed.). Fruteiras de caroço: uma visão ecológica. Curitiba : UFPR, 2004, p.1-4. 